\title{
Construction and Application of Heluo Culture Big Data Platform Based on Basic Framework of Hadoop
}

\author{
Hongsheng $\mathrm{Xu}^{1,2 \mathrm{a}^{*}}$, Ganglong $\mathrm{Fan}^{1,2}$ and Xiaokang Qin ${ }^{1,2}$ \\ ${ }^{1}$ Luoyang Normal University, Luoyang, 471934, China \\ ${ }^{2}$ Henan key Laboratory for Big Data Processing \& Analytics of Electronic Commerce, Luoyang, \\ 471934, China \\ a85660190@qq.com
}

*The corresponding author

Keywords: Heluo culture; Big data; Hadoop; VR; Animation production

\begin{abstract}
Heluo culture is the core of Chinese culture and Yellow River culture and it is an important part of the Central Plains culture, and also the essence and mainstream of Chinese traditional culture. Through collecting, cleaning, analyzing, sharing, visual research and development of big data of Heluo culture, this paper improves the technical service ability and application development level of big data. The paper presents construction and application of Heluo Culture big data platform based on basic Framework of Hadoop. Big data sharing platform including Heluo culture digital museum, animation and visual cloud services.
\end{abstract}

\section{Introduction}

Heluo culture is the core of Chinese culture and Yellow River culture. It is extensive and profound and has a long history. It is an important part of the Central Plains culture and also the essence and mainstream of Chinese traditional culture. In view of this, the project application team bases on talents. Geographical location and other advantages of the selection of national characteristics of Heluo culture, the construction of big data heluo culture sharing platform, in order to provide reference for the construction of national culture big data sharing platform [1].

In the process of the development of prehistoric culture in China and the cultural development after entering the civilized society, the culture of the Central Plains, especially the culture of Heluo, has always played a central and guiding role, thus becoming the core of the Chinese civilization. He Luo culture is different from any regional culture, such as Shandong Qilu culture, Hebei Yanzhao culture, Shanxi Jin culture, Shaanxi Qin culture, Sichuan's Bashu culture, the Jingchu culture of the two lakes, the $\mathrm{Wu}$ Yue culture of Jiangsu and Zhejiang, etc. It is the central culture, the national culture, the national capital culture, the ruling culture, which has occupied a dominant position for a long time and has become the source and core of the ancient Chinese culture [2]. Constitute the most important part of Chinese traditional culture.

At present, under the influence of the rapid development of big data and cloud computing technologies, the world has been covered by a large amount of information, and the building of big data platform can effectively realize the national politics, economy and society [3]. The construction of cultural big data's platform is an important way to make great progress in the construction of socialist cultural power in China and to further improve the soft power of national culture.

In this paper, big data's platform is based on the commercial version of Hadoop, including functional modules such as big data analysis, data mining, machine learning, and HDFS and Hbase as the storage basis.

Hadoop distributed file system is designed to be suitable for running on general hardware. It has a lot in common with the existing distributed file system. But at the same time, the difference between it and other distributed file systems is also obvious [4]. HDFS is a highly fault-tolerant system suitable for deployment on cheap machines. HDFS provides high throughput data access. It is very suitable for 
large-scale data set applications. HDFSs relax some of the POSIX constraints to achieve the purpose of streaming reading file system data.

To carry out a survey on the development of Heluo culture, formulate a development plan for big data's platform, establish an interdisciplinary and multi-domain coordination mechanism, set up an advisory committee of experts on Heluo culture, and complete the list of lists for the sharing of data and resources of Heluo culture [5]. To formulate service standards for cultural big data, and it is promote the establishment of a comprehensive service platform.

To investigate the data resources of libraries, museums, cultural centers, art galleries, art academies and art and scientific research institutes, etc., Grasp the basic data storage and increment of Heluo culture, to build a platform for sharing Heluo culture with big data. Through collecting, cleaning, analyzing, sharing, visualizing research and development of big data of Heluo culture, we can improve the technical service ability and application development level of big data. By integrating big data's core technology with the characteristics of Heluo culture, and constructing the industrial chain and practical application, we can expand the extension of Haluo culture sharing big data platform.

\section{Reconstruction of Heluo Culture based on VR Technology}

At present, VR interaction is still being explored and studied, and the combination with various high technologies will make VR interaction infinitely possible. VR will not have a universal means of interaction. It has a richer form of interaction than graphic interaction. Virtual reality draws people closer and closer to each other, and it's no longer just using the Internet for people to interact with each other. It also draws people closer physically [6]. Combining existing research bases and technological forces, we study and develop the use of Internet virtual technology and human-computer interaction technology in reality, so that they can be closer to life and work. Better serve the public.

Relying on the key research base of humanities and social sciences in ordinary colleges and universities of Henan Province Heluo Culture Research Center, and the talents and scientific research advantages and hardware foundation of key laboratory of virtual reproduction of Huoluo Culture in Luoyang City, Build two dimensional paperless animation, motion capture, special effects synthesis, animation rendering, audio editing and other virtual reproduction technology service platform, build the website of virtual reappearance of helo culture, the electronic publication of helo culture, realize Longmen, White Horse Temple, etc. Zhou Wangling, Erlitou and other historical sites, such as the virtual reproduction of historical events, such as Wu Zetian's accession to the throne, Luoyang Taixue lecture, and so on, the virtual reproduction of works of art of the Hollow stone carvings in the library of the normal University, and the virtual reproduction of precious cultural relics in the Luoyang Museum.

A study on the region of Heluo and the scope of it is Cultural Circle. According to Zhu Shaohou, the historical Heluo region "refers to Luoyang as the center, west to Tongguan, Huayin, east to Xingyang, Zhengzhou to Ruying in the south, and north to the south of the Yellow River to Jinnan," Jiyuan area "." the cultural circle of Heluo should cover all areas of Henan Province at present, link up with Qilu cultural circle in the east, link up with Chu cultural circle in the south, link up with Qin Jin in the west and link up with the Yanzhao cultural circle in the north; Li Shaolian said: "'he Luo'is a geographical concept, specifically refers to the intersection of the Yellow River and the Luohe region, namely the Yellow River 'three rivers' and the Luohe City [7].

The study of Heluo culture, the combination of Chinese characters origin and Internet technology. The Heluo culture created by the ancestors in Heluo area is the core and birthplace of the Yellow River civilization represented by the Central Plains culture, which is the cradle culture of Chinese civilization [8]. It is the main body of Chinese traditional culture for thousands of years, so the culture of Heluo occupies a very important position in the history of ancient Chinese culture.

Based on the research of virtual technology and human-computer interaction technology and the wider use of animation, the spread of animation in this field is studied, so that the audience and the animated characters can be more closely contacted, so as to achieve a better perception and experience. Based on the combination of 2D and 3D animation technology and virtual reality technology, combined with expert knowledge in the field, the virtual reality experience hall of animation is constructed to 
provide the audience with a new mode of viewing and feeling of animation products, and take advantage of the opportunity to develop electronic commerce platform of animation products. Form a supporting sales model.

Based on the use of virtual reality technology, the DIY platform of virtual reality works is constructed for all levels of consumers [9]. Through the platform, consumers can create personalized products on their own, and further improve the efficiency of using virtual reality technology. To enable consumers to achieve a better experience, promote the dissemination and use of the technology.

The concept of Heluo culture, research and development of the connotation of Cheng Youwei "Introduction to Heluo culture summarized four representative viewpoints: the first one is understanding that Heluo culture is an ancient culture, the lower limit is the establishment of the Xia. Zhang Zhenli said:" the narrow sense of Heluo culture is the hinterland of the Central Plains of Iraq. The second is at the end of the Warring States. Sun Jia Zhou believes that Heluo culture and other regional culture, to the Qin Dynasty after the reunification has ceased to exist.

\section{Analysis of the Basic Architecture and Key Technology of Big Data Platform}

Big data platform tasks: infrastructure support. Mainly includes infrastructure level data center management, cloud computing platform, cloud storage equipment and technology, network technology, Big data deals with cloud data centers with large-scale physical resources and cloud computing platforms with efficient scheduling and management capabilities.

Hadoop can automatically save multiple copies of data, and can automatically fail Retasking. Hadoop framework with Java language, so the operation in the Linux production platform is ideal for.Hadoop applications can also use other languages, such as $\mathrm{C}++$.

OpenStack is an open source cloud computing virtual architecture that users can use to build and run their cloud computing and storage architectures [10]. The client tools written for Amazon Web Service (OpenStack) can also be used together with OpenStack. OpenStack is the best way to decouple SOA and service components. The overall architecture of .OpenStack is divided into three layers, and the top layer is the access layer such as the application program and the management portal, such as the Horizonnberg API. The core layer includes computing service Nova, storage service (including object storage service Swift and block storage service Cinder) and network service Quantumn; layer 3 is shared service, now account rights management service keystone) and mirror service.

The ETL tool in the process of data acquisition is responsible for extracting the distributed and heterogeneous data of different kinds and structures such as text data, relational data, pictures, video and other unstructured data into the temporary middle layer for cleaning. Conversion, classification, integration, and finally loading into the corresponding data storage system, such as data warehouse or data Mart, become the basis of online analytical processing and data mining. The ETL tool for big data is different from the traditional ETL processing process at the same time. Because on the one hand big data's volume is huge, on the other hand, the speed of data generation is also very fast. For example, the video surveillance head of a city, the intelligent electric meter generates a large amount of data every second, and the preprocessing of the data needs to be real time and fast. Therefore, modern information technologies such as distributed memory database, real-time stream processing system and so on will be used in ETL architecture and tool selection.

Big data's processing platform technology, represented by Hadoop platform, including MapReduceHBase, HiveZookeeperv Avro and Pig, has formed a Hadoop Biosphere MapReduce programming model, which is the heart of Hadoop and is used for parallel operation of large-scale data sets. Large scale scalability across hundreds or thousands of servers in a Hadoop cluster is achieved. The distributed file system HDFS provides massive data storage based on Hadoop processing platform. The NameNode provides the metadata service data Node for storing file system file blocks. 


\section{Construction and Application of Heluo Culture Big Data Platform Based on Basic Framework of Hadoop}

According to the resource types of Heluo culture, a digital museum with clear modules, comprehensive coverage and various presentation modes is constructed. The resource types of helo culture are mainly divided into: site culture, religious culture, folk culture, celebrity culture, etc. The establishment of Hollow Culture Digital Museum can promote cultural tourism, entertainment and leisure, festivals and exhibitions, film and television, publishing and printing, arts and crafts, creative design, network culture, cultural performing arts, digital services; therefore, the integration of rich and diverse cultural resources is the most important.

Heluo culture can be spread in the form of animation, based on the use of virtual reality technology and human-computer interaction technology, for all levels of consumers, building virtual reality works DIY platform, through the platform to achieve consumer self-creation of personalized products, Further improve the use of virtual reality technology efficiency, so that consumers can achieve a better experience. Animation types include historical stories, biographies, Chinese characters promotion, according to the audience's age stratification, production suitable for infants, teenagers, Young and middle-aged, the elderly watching the experience of animation works.

He Luo Dagu is one of the traditional local music species in Henan Province. It is a kind of art performance means of saying and singing, narrating stories, shaping characters, expressing thoughts and feelings. The local people call the river Luo Dagu "storytelling", and up to now they often link the "storytelling and singing plays" in Luoyang. There are eleven kinds of word signs in their artistic forms, and famous artists are these.

From the government point of view: the construction of big data sharing platform of Heluo Culture can effectively realize data sharing and enable government market supervision departments, tourism and environmental protection departments, public security departments, credit information departments, social security departments, housing and construction departments. Grasp the real-time and effective development situation in Heluo culture area.

Big data sharing platform includes helo cultural digital museum, animation works and visual cloud service. According to the online updated real-time data, the public can select the attractive Horo Culture Scenic area, and visit the site to learn to observe.

Big data sharing platform of Heluo Culture will be collected and arranged through the basic information, the construction of digital museum and the construction of famous scene of Heluo Culture with the help of virtual reproduction technology. To promote the development of Heluo cultural tourism projects, such as the virtual reproduction of excellent cultural tourism projects such as the town of Tangwenchuang in Bali, Shangyang Palace Cultural Park, Luoyang City living Room, Longyuwan and so on, to promote the development of cultural tourism projects.

Unified development: integrated graphical development interface, through the unified encapsulated function library to provide SQL class development language, in order to shield the underlying platform differences, reduce the development threshold of business personnel, through the data model abstraction of metadata, the background data resources of Hadoop DB2 are opened to the front end which is efficient, safe and controllable.

The big data platform will focus on the industrial application of Heluo culture, and through the direction of animation production in the cultural industry, it will be based on virtual technology and human-computer interaction technology research and wider use. This paper studies the communication advantages of animations with the theme of Heluo culture in China, innovates the animation form, makes the audience and the animated characters more intimate contact, and achieves a better perception and experience. Based on the combination of 2D and 3D animation technology and virtual reality technology, combined with expert knowledge in the field of animation, the virtual reality experience hall of animation is constructed to provide the audience with a new mode of viewing and feeling of animation products, and to develop the electronic commerce platform of animation products. Form a supporting sales model. 


\section{Summary}

The construction of big data sharing platform of Heluo Culture provides cloud service support. The purpose of this platform is to realize the dynamic, intelligent, visualized and real-time sharing platform of big data and can obtain data information from big data sharing platform of Heluo Culture. The ultimate purpose of the platform is to serve the public. When users search the key words of Heluo culture in the platform, they should make full use of big data retrieval technology. Based on the analysis of user keywords, the search results are displayed in the form of video, text and image.

\section{Acknowledgements}

This paper is supported by Henan key Laboratory for Big Data Processing \& Analytics of Electronic Commerce, and also supported by the science and technology research major project of Henan province Education Department (17B520026).

\section{References}

[1] Li Shaolian.A brief discussion on Heluo Culture and Chinese traditional Culture, Journal of the Yellow River University of Science and Technology, 2008,(06): 28-31.

[2] Zhang Xinbin, Heluo Culture and Luoyang School of Science and Technology, Journal of Central State , 2016, ( 12 ):126-132.

[3] Hongsheng Xu, Ruiling Zhang. Novel Approach of Semantic Annotation by Fuzzy Ontology based on Variable Precision Rough Set and Concept Lattice, International Journal of Hybrid Information Technology Vol.9, No.4 (2016), pp. 25-40.

[4] Yang Xiang-ming, Digital Museum and its related problems, Cultural relics of the Central Plains, 2006,(1): 93-96.

[5] H.-s. XU, R.-1. ZHANG, "Semantic Annotation of Ontology by Using Rough Concept Lattice Isomorphic Model", International Journal of Hybrid Information Technology, Vol.8, No.2, 2015, pp.93-108.

[6] Zhang Zhengdong, A preliminary study on the Construction of the Chinese Hakka Cultural Digital Museum based on 3s, Journal of Jiaying College, 2004,(04),08-70.

[7] Liu Shijun, Meng Xiangxu, Xiang Hui. Research on data Integration of the Digital Museum of Cultural relics based on XML, Journal of system Simulation, 2002,12: 1624-1627.

[8] Lei J, Ye H J, et al.Research and Development of big data platform based on Open Source ecosystem, computer Research and Development, 2017: 54 (1): 80-93.

[9] Chen Xueqi, Jin Xiaolong, big data system and Analytical Technology Summary, Journal of Software, 2014(9): 1889-1908.

[10] Zhang Dongxia, Miao Xin, Research on Technical Development of big data in Smart Grid, Chinese Journal of Electrical Engineering, 2015(1):2-12. 